\title{
Cullin 7 is a predictor of poor prognosis in breast cancer patients and is involved in the proliferation and invasion of breast cancer cells by regulating the cell cycle and microtubule stability
}

\author{
NI QIU, YUFANG HE, SIMING ZHANG, XINPENG HU, MINGSHENG CHEN and HONGSHENG LI \\ Department of Breast Surgery, Affiliated Cancer Hospital and Institute of Guangzhou Medical University, \\ Guangzhou, Guangdong 510095, P.R. China
}

Received March 23, 2017; Accepted August 23, 2017

DOI: 10.3892/or.2017.6106

\begin{abstract}
Cullin 7 is the 'scaffold' of the cullin-RING-based E3 ligases which catalyze the final step of the ubiquitination cascade in eukaryotic organisms. Although one study has reported the involvement of cullin 7 in the invasion and migration of breast cancer cells without further exploration of its mechanisms, the expression of cullin 7 in breast cancer tissues and its clinical significance have not been reported. The present study evaluated cullin 7 protein expression in malignant and benign breast tissues using immunochemistry, and further analyzed the association of positive cullin 7 expression in breast cancer tissues with clinicopathological characteristics of breast cancer patients. Cullin 7 expression was further silenced in breast cancer cells by siRNA and its functions and mechanisms in cell proliferation and invasion were investigated. The results showed that high cullin 7 expression was significantly correlated with pathological stage $(\mathrm{P}=0.013)$ and lymph node metastasis $(\mathrm{P}=0.022)$ of breast cancer. Patients with high cullin 7 expression had a shorter overall survival rate than those with low cullin 7 expression $(\mathrm{P}=0.037)$. Silencing of cullin 7 expression significantly inhibited the proliferation $(\mathrm{P}<0.05)$ and invasion $(\mathrm{P}<0.05)$, increased $\mathrm{S} 1$ phase $(\mathrm{P}<0.05)$, but decreased $\mathrm{G} 2$ phase $(\mathrm{P}<0.05)$ in MDA-MB-231 and BT549 cells. In addition, silencing of cullin 7 expression decreased cyclin A, but increased p21 protein expression. Moreover, silencing of cullin 7 expression altered the cell shape, caused disorder in microtubules, and increased the microtubule regeneration in MDA-MB-231 and BT549 cells. In conclusion, cullin 7 is overexpressed in breast cancer tissues which is associated with the development and prognosis of breast cancer. Cullin 7 is involved in the proliferation and invasion of
\end{abstract}

Correspondence to: Dr Hongsheng Li, Department of Breast Surgery, Affiliated Cancer Hospital and Institute of Guangzhou Medical University, Guangzhou, Guangdong 510095, P.R. China E-mail: docli999@163.com

Key words: breast cancer, cullin 7, prognostic, microtubule dynamics, proliferation, migration, invasion breast cancer cells by regulating the cell cycle and microtubule stability.

\section{Introduction}

The ubiquitin proteasome system is the main pathway for protein degradation in eukaryotic organisms. Proteins are first ubiquitylated through 3 main steps: activation, conjugation and ligation, performed by ubiquitin-activating enzymes (E1s), ubiquitin-conjugating enzymes (E2s) and ubiquitin ligases (E3s), respectively; ubiquitylated proteins are then degraded by proteasomes. E3 ubiquitin ligases catalyze the final, but key step of the ubiquitination cascade through the specific recognition of the substrate target protein and E2 $(1,2)$. It has been found that the RING-finger family is a major member of the E3 family. Most members of the RING-finger E3 ligase family are complexes of multiple molecules, in which the cullin-RING-based E3 ligases (CRLs) form the main body of such ubiquitin ligases (3). Cullin is a 'scaffold' of a CRL, which is linked to E2 through its $\mathrm{C}$ terminal binding to the Roc1 protein and linked to the substrate protein through its $\mathrm{N}$ terminal binding to different F-box proteins. The cullin-E3 ligase family can recognize a variety of substrates including molecules involved in signal transduction (SMAD3/4 and Notch1/4), transcriptional regulation (E2F1 and HIF1), DNA replication (CDT1 and ORC1) and growth and development (E2A); it plays an important role in maintaining normal and steady cell growth (4).

Numerous studies have found that the abnormal expression of cullin protein family members are closely related to the occurrence, development, metastasis and recurrence of various malignant tumors (5). For example, Min et al study demonstrated that the expression of cullin 1 in breast cancer cells is positively correlated with the expression of p53 and regulates cell apoptosis (6). Cullin 3 accelerates the progression of breast cancer by regulating the effect of speckle-type POZ protein on the expression of breast cancer metastasis suppressor 1 (7). The overexpression of cullin 4A promotes growth and metastasis of basal-like breast tumors (8). Cullin 7 is one of the structural components of E3 ubiquitin ligases and functions as an oncogene to play a critical role in the proliferation and differentiation of pancreatic cancer cells (9). Cullin 7 
inhibits Myc-induced apoptosis and promotes Myc-mediated malignant transformation of cells (10). Cullin 7 inhibits p53-dependent DNA repair function (11) and activates EMT in choriocarcinoma (12).

Our previous study using whole genome exon sequencing found that cullin 7 was one of the 12 metastatic candidate genes (13). Guo et al reported high cullin 7 protein expression in breast cancer specimen, but its clinical significance was not addressed (11). They also reported that forced expression of cullin 7 enhances cell migration and invasion in human breast cancer cells (11), but the mechanisms were not addressed. In the present study, we detected cullin 7 protein expression in normal, benign and malignant breast tissues, and then analyzed the correlation of cullin 7 expression in breast cancer tissues in regards to various clinicopathological characteristics and estrogen receptor (ER), progesterone receptor (PR) and human epidermal growth factor receptor-2 (HER-2) expression. The present study also investigated the effects and mechanism of cullin 7 in breast cancer cell proliferation and invasion.

\section{Materials and methods}

Samples. The use of tissue specimens was approved by the Ethics Committee of the Affiliated Cancer Hospital, Guangzhou Medical University. The specimens of 13 normal breast tissues, 20 benign breast tumors and 93 breast cancer tissues were used for the present study. Paraffin-embedded tissue samples were obtained from the Department of Pathology, Affiliated Tumor Hospital, Guangzhou Medical University. Of the 93 breast cancer patients, 52 had lymph node metastasis and 41 had no lymph node metastasis.

Immunohistochemistry. Cullin 7 protein expression in tissues was measured by immunohistochemical staining. Briefly, tissue sections were dewaxed, rehydrated, followed by incubation with $3 \%$ hydrogen peroxide for $10 \mathrm{~min}$ and antigen retrieval in $100 \mathrm{mM}$ Tris $\left(\mathrm{pH} \mathrm{10.0)}\right.$ at $98^{\circ} \mathrm{C}$ for $30 \mathrm{~min}$. The slices were then blocked with $2.5 \%$ horse serum and incubated with biotin-labeled cullin 7 primary antibody (1:200 dilution; Abcam, Guangzhou, China) overnight at $4^{\circ} \mathrm{C}$ followed by incubation with the avidin-biotin complex according to the user manual (Vector Laboratories, Guangzhou, China). After counterstaining with hematoxylin, the staining was scored: 0 score for negative staining, 1 for weak staining, 2 for moderate staining, and 3 for strong staining.

Cell culture. MDA-MB-231 and BT549 cells were cultured in RPMI-1640 medium containing 10\% fetal calf serum (FCS) (Invitrogen, Carlsbad, CA, USA). HS578T, MCF7, T47D, SKBR3 and BT474 cells were cultured in Dulbecco's modified Eagle's medium (DMEM) containing 10\% FCS. Cells were cultured at $37^{\circ} \mathrm{C}$ in $5 \% \mathrm{CO}_{2}$.

Establishment of stable cells expressing cullin 7 siRNA. MDA-MB-231 and BT549 stable cells expressing cullin 7 siRNA were established by lentivirus infections by following the manufacturer's instructions; the produced stable cells were called 231-siCul7 and 549-siCul7, respectively. MDA-MB-231 and BT549 control stable cells (231-siCtrl and 549-siCtrl, respectively were produced to express control small interference RNA (siRNA) not targeting any gene using lentivirus infection. The cullin 7 and control lentiviral particles were purchased from Shanghai GeneChem Co., Ltd. (Shanghai, China).

Western blot analysis. Cells $\left(1 \times 10^{6}\right)$ were homogenized in $100 \mu 1$ of RIPA buffer on ice for $30 \mathrm{~min}$ and mixed for $15 \mathrm{sec}$ every $5 \mathrm{~min}$. After centrifuging at $12,000 \mathrm{rpm}$ for $10 \mathrm{~min}$ at $4^{\circ} \mathrm{C}$, the supernatant was harvested and protein concentration was measured using a Pierce BCA protein assay kit (Thermo Fisher Scientific, Waltham, MA, USA). Total protein $(10 \mu \mathrm{g})$ was separated by electrophoresis on $10 \%$ sodium dodecyl sulfate-polyacrylamide gel. After being transferred to polyvinylidene difluoride membranes, the membranes were blocked with 5\% non-fat milk in Tris-buffered saline (TBS) buffer at room temperature (RT) for $1 \mathrm{~h}$, followed by incubation with anti-cullin 7, anti-cyclin A and anti-p21 antibody (Abcam) overnight at $4^{\circ} \mathrm{C}$. After washing with $1 \mathrm{X}$ TBS $+0.1 \%$ Tween-20 (TBST) buffer for $3 \times 10 \mathrm{~min}$, the membranes were incubated with secondary antibody for $1 \mathrm{~h}$ at RT. The immune reaction was visualized using enhanced chemiluminescence (Pierce, Waltham, MA, USA). The bands on X-ray film were scanned using Quantity One software.

Cell viability assay. Cell viability was measured using the Cell Counting Kit-8 (CCK-8) kit by following the manufacturer's instructions (Sigma-Aldrich, Beijing, China). Briefly, 1,000 of 231-siCul7, 549-siCul7, 231-siCtrl and 549-siCtrl cells in $0.1 \mathrm{ml}$ medium containing $10 \%$ FCS were seeded in each well of 96-well plates. Twenty-four hours later, $10 \mu \mathrm{l}$ of CCK-8 solution was added to each well and cells were continuously incubated for $2 \mathrm{~h}$. The absorbance was measured at a wavelength of $450 \mathrm{~nm}$.

Flow cytometry. 231-siCu17, 549-siCul7, 231-siCtrl and 549-siCtrl cells were seeded in 6-well plates and treated for $24 \mathrm{~h}$ after having attached. The cells were then harvested by a centrifuge at 1,000 rpm for $5 \mathrm{~min}$. After washing the pellets with $1 \mathrm{ml}$ of phosphate-buffered saline (PBS), cells were re-suspended with $3 \mathrm{ml}$ of pre-cooled anhydrous ethanol and placed at $-20^{\circ} \mathrm{C}$ overnight. After washing with $1 \mathrm{ml} \mathrm{PBS}$ at $4{ }^{\circ} \mathrm{C}$, cells were re-suspended in $1 \mathrm{ml}$ of pre-cooled PBS and $400 \mu \mathrm{l}$ of propidium iodide (PI) staining solution (Sigma-Aldrich). After incubation for $30 \mathrm{~min}$ at $4^{\circ} \mathrm{C}$, cells were subjected to flow cytometry assay (BD Biosciences, Franklin Lakes, NJ, USA).

In vitro tumor invasion assay. 231-siCul7, 549-siCul7, 231-siCtrl and 549-siCtrl cells were cultured in $10-\mathrm{cm}$ dish to $80 \%$ confluency and digested with $0.25 \%$ trypsin and re-suspended in complete medium at $5 \times 10^{4}$ cells $/ \mathrm{ml}$. Of cells $(0.5 \mathrm{ml})$ was transferred into Transwell covered with Matrigel and continuously cultured for $24 \mathrm{~h}$. The cells that migrated to the membranes at the lower chamber were fixed with ice precooled methanol for $30 \mathrm{~min}$, and stained with $1 \%$ crystal violet for $10 \mathrm{~min}$. Cells on the membranes were observed under a microscope.

Cell microtubule regeneration analysis. The adherent cultured 231-siCul7, 549-siCul7, 231-siCtrl and 549-siCtrl cells were incubated with a medium containing $10 \mathrm{mM}$ nocodazole 
A
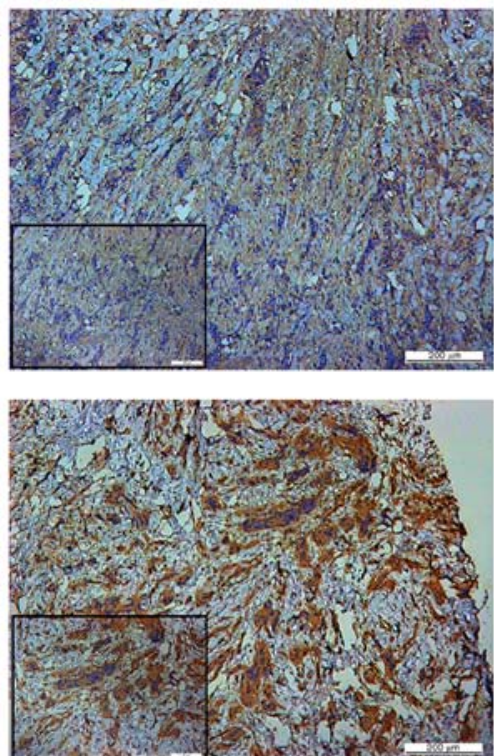

C

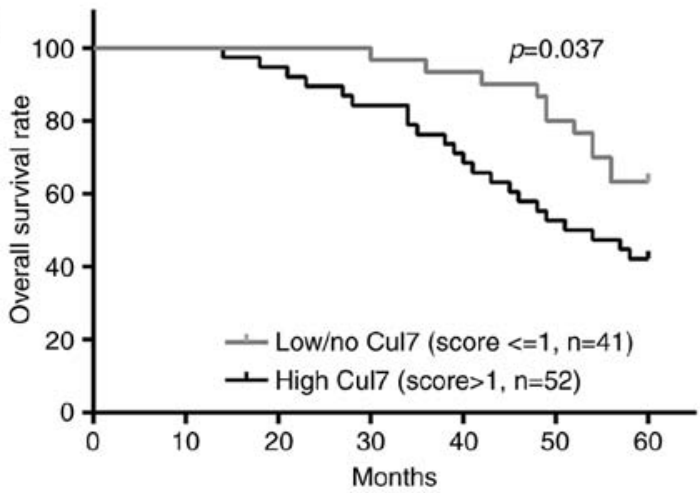

B
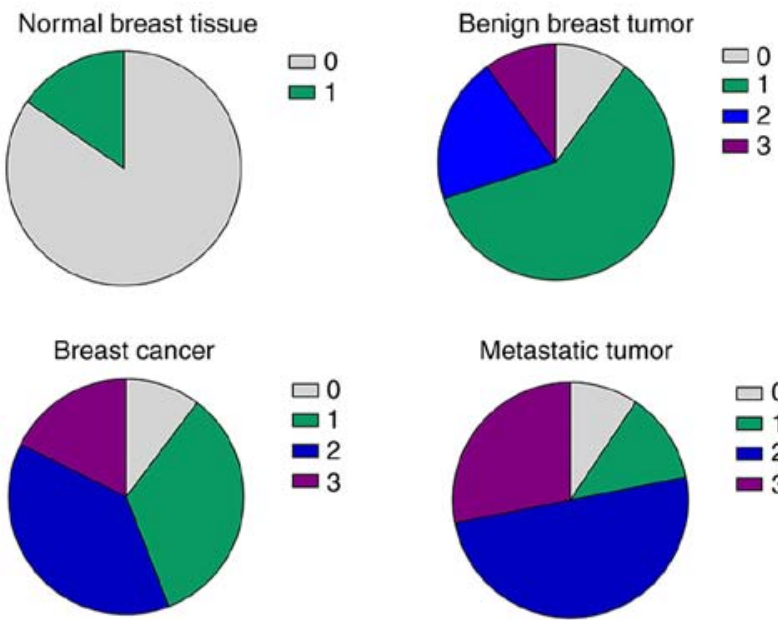

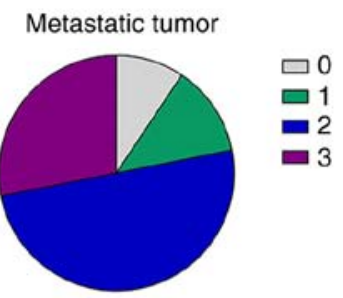

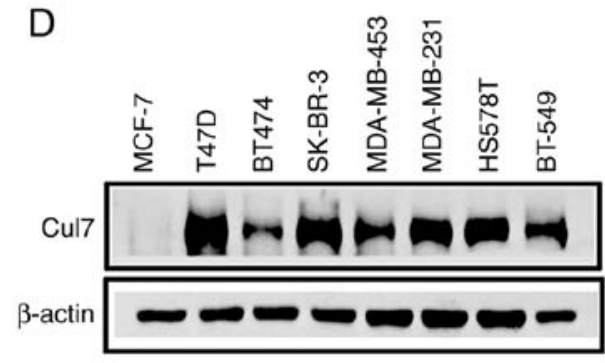

Figure 1. Expression of cullin 7 (Cul7) in breast cancer tissues and cell lines. (A) Representative immunohistochemistry of cullin 7 protein expression in tumor tissues with staining intensity of 1+ (weak, upper), and 3+ (strong, lower) score. (B) Distribution of immunoreactivity scores in normal breast tissue, benign breast tumor, breast cancer tissues and lymph node metastasis. The staining intensity was scored from 0 to $3+$. (C) Kaplan-Meier plots of cullin 7 (Cul7) expression in 93 breast cancer patients. Immunoreactivity scores of $0-1$ were ascribed to low cullin 7 expression, while immunoreactivity scores of 2-3 were ascribed to be high cullin 7 expression. (D) Western blotting of cullin 7 and $\beta$-actin protein expression in breast cancer cell lines.

for $2 \mathrm{~h}$ to completely depolymerize the microtubules in the cells. The medium containing nocodazole was then replaced with fresh medium and incubated in a $\mathrm{CO}_{2}$ incubator at $37^{\circ} \mathrm{C}$. The microtubules in the cells were re-polymerized in a process called microtubule regeneration (14). Ten minutes after microtubule regeneration, cells were treated with PEMT buffer (100 mM PIPES, $1 \mathrm{mM}$ EGTA, $0.5 \mathrm{mM} \mathrm{MgCl}_{2}, 0.5 \%$ Triton $\mathrm{X}-100, \mathrm{pH}$ 6.9) for $30 \mathrm{~min}$ and then fixed with $4 \%$ paraformaldehyde at RT for 30 min or fixed with pre-cooled methanol for $5 \mathrm{~min}$. After blocking with $2 \%$ bovine serum albumin for $1 \mathrm{~h}$ at RT, cells were incubated with anti- $\alpha$-tubulin antibody (Cell Signaling Technology, Guangzhou, China) for $2 \mathrm{~h}$ followed by secondary antibody for $1 \mathrm{~h}$ at RT after washing with PBS. Cells were then incubated with 4',6-diamidino2-phenylindole (1:500 dilution) for $5 \mathrm{~min}$ at RT, and then observed under a fluorescence microscope.

Tumor growth. Animal experiments were approved by the Animal Ethics Committee of Guangzhou Medical University. Male nude mice at 6 weeks old were inoculated with $0.5 \times 10^{6}$ of 231-siCul7 and 231-siCtrl cells on the left back proximal axillary. Tumor growth was observed every 3 days. Nude mice were sacrificed, tumors were excised on the 48th day after inoculation, and the tumor volume and weight were assessed.

Statistical analysis. The correlations of positive cullin 7 protein expression in breast cancer tissues with the clinicopathological characteristics of patients were analyzed using $\chi^{2}$ test. The association of immunohistochemical staining with the patients prognosis was analyzed using Kaplan-Meier survival analysis. The correlation between cullin 7 protein expression and ER, PR and HER-2 expression in breast cancer tissues was analyzed using Spearman correlation analysis. Measurement of data between 2 groups of samples was carried out using the Student's t-test. $\mathrm{P}<0.05$ was considered statistically significant.

\section{Results}

Expression of cullin 7 is positively correlated with the malignancy of breast cancer. The expression of cullin 7 protein in normal breast tissues, breast benign legions, breast cancer tissues, and axillary lymph nodes of breast cancer patients was detected by immunohistochemistry (Fig. 1A). Cullin 7 was negatively or weakly expressed in normal breast tissues, 
Table I. Cullin 7 staining and clinicopathological characteristics of the 93 breast cancer patients.

\begin{tabular}{|c|c|c|c|c|}
\hline \multirow[b]{2}{*}{ Variables } & \multicolumn{2}{|c|}{ Cullin 7 staining } & \multirow[b]{2}{*}{ Total } & \multirow[b]{2}{*}{ P-value } \\
\hline & Negative or low (\%) & High positive $(\%)$ & & \\
\hline Age (years) & & & & 0.536 \\
\hline$\leq 50$ & $20(40.8)$ & $29(59.2)$ & 49 & \\
\hline$>50$ & $21(47.7)$ & $23(52.3)$ & 44 & \\
\hline Tumor size (cm) & & & & 0.493 \\
\hline $\mathrm{T} 1(<2)$ & $10(37.1)$ & $17(62.9)$ & 27 & \\
\hline $\mathrm{T} 2(2-5)$ & $20(48.7)$ & $21(51.3)$ & 41 & \\
\hline $\mathrm{T} 3(>5)$ & $9(36.0)$ & $16(64.0)$ & 25 & \\
\hline Lymph node metastasis & & & & $0.022^{\mathrm{a}}$ \\
\hline Negative & $24(58.5)$ & $17(41.5)$ & 41 & \\
\hline Positive & $18(34.6)$ & $34(65.4)$ & 52 & \\
\hline Histologic grade & & & & $0.013^{\mathrm{a}}$ \\
\hline I & $19(79.2)$ & $8(20.8)$ & 24 & \\
\hline II & $25(65.8)$ & $14(34.2)$ & 38 & \\
\hline III & $10(32.2)$ & $19(67.8)$ & 31 & \\
\hline Histologic type & & & & 0.990 \\
\hline Ductal & $35(45.4)$ & $42(54.6)$ & 77 & \\
\hline Lobular & $4(44.4)$ & $5(55.6)$ & 9 & \\
\hline Other & $3(42.8)$ & $4(57.2)$ & 7 & \\
\hline ER status & & & & 0.336 \\
\hline Negative & $22(56.4)$ & $17(43.6)$ & 39 & \\
\hline Positive & $25(46.3)$ & $29(53.7)$ & 54 & \\
\hline PR status & & & & 0.808 \\
\hline Negative & 20 (47.6) & $22(52.4)$ & 42 & \\
\hline Positive & $23(45.1)$ & $28(54.9)$ & 51 & \\
\hline HER-2 status & & & & 0.384 \\
\hline Negative & $30(56.6)$ & $23(43.4)$ & 53 & \\
\hline Positive & $19(47.5)$ & $21(52.5)$ & 40 & \\
\hline
\end{tabular}

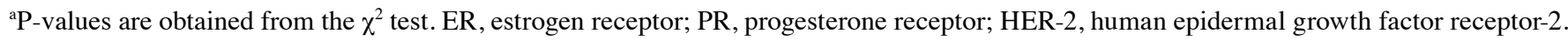

but its expression in benign breast tumor tissues was increased (30.9\% positive) compared to the normal breast tissues. The percentage of positive cullin 7 protein expression was $55.9 \%$ in breast cancer tissues and $78.1 \%$ in the axillary lymph nodes of breast cancer patients (Fig. 1B).

Positive cullin 7 expression in breast cancer patients was significantly associated with the tumor, lymph node, metastasis (TNM) staging, such as that the percentage of positive cullin 7 expression was significantly lower in tumor tissues in patients with early breast cancer than that of patients with advanced disease. The expression of cullin 7 was significantly higher in poorly differentiated tumor tissues than that in well differentiated tumor tissues. The expression of cullin 7 was positively associated with histological grade of breast cancer $(\mathrm{P}=0.013)$ and axillary lymph node metastasis in breast cancer patients $(\mathrm{P}=0.022)$. No significant correlations were observed between cullin 7 expression and age, tumor size and pathological type $(\mathrm{P}>0.05)$, as well as ER, PR and HER-2 expression in breast cancer tissues $(\mathrm{P}>0.05)$ (Table I).
Kaplan-Meier survival analysis showed that the expression of cullin 7 was negatively correlated with the overall survival rate of breast cancer patients. The 5-year survival rate of patients with high cullin 7 expression was significantly lower than that of patients with low cullin 7 expression $(\mathrm{P}<0.05)$ (Fig. 1C). In addition, cullin 7 was highly expressed in breast cancer cell lines with high metastatic capacity, such as MDA-MB-231, BT549 and HS578T and lowly expressed in poorly metastatic breast cancer cell lines, such as MCF-7 and BT474 (Fig. 1D). These results suggest that cullin 7 plays an important role in the metastasis and progression of breast cancer.

Cullin7 is involved in the proliferation of breast cancer cells. Western blotting showed that cullin 7 protein expression was significantly decreased in 231-siCul7 and 549-siCul stable cells compared to that in 231-siCtrl and 549-siCtrl stable control cells, respectively (Fig. 2A). Cell viability assay using the CCK-8 kit showed that the cell proliferation ability was significantly reduced in the 231-siCul7 and 549-siCul stable 

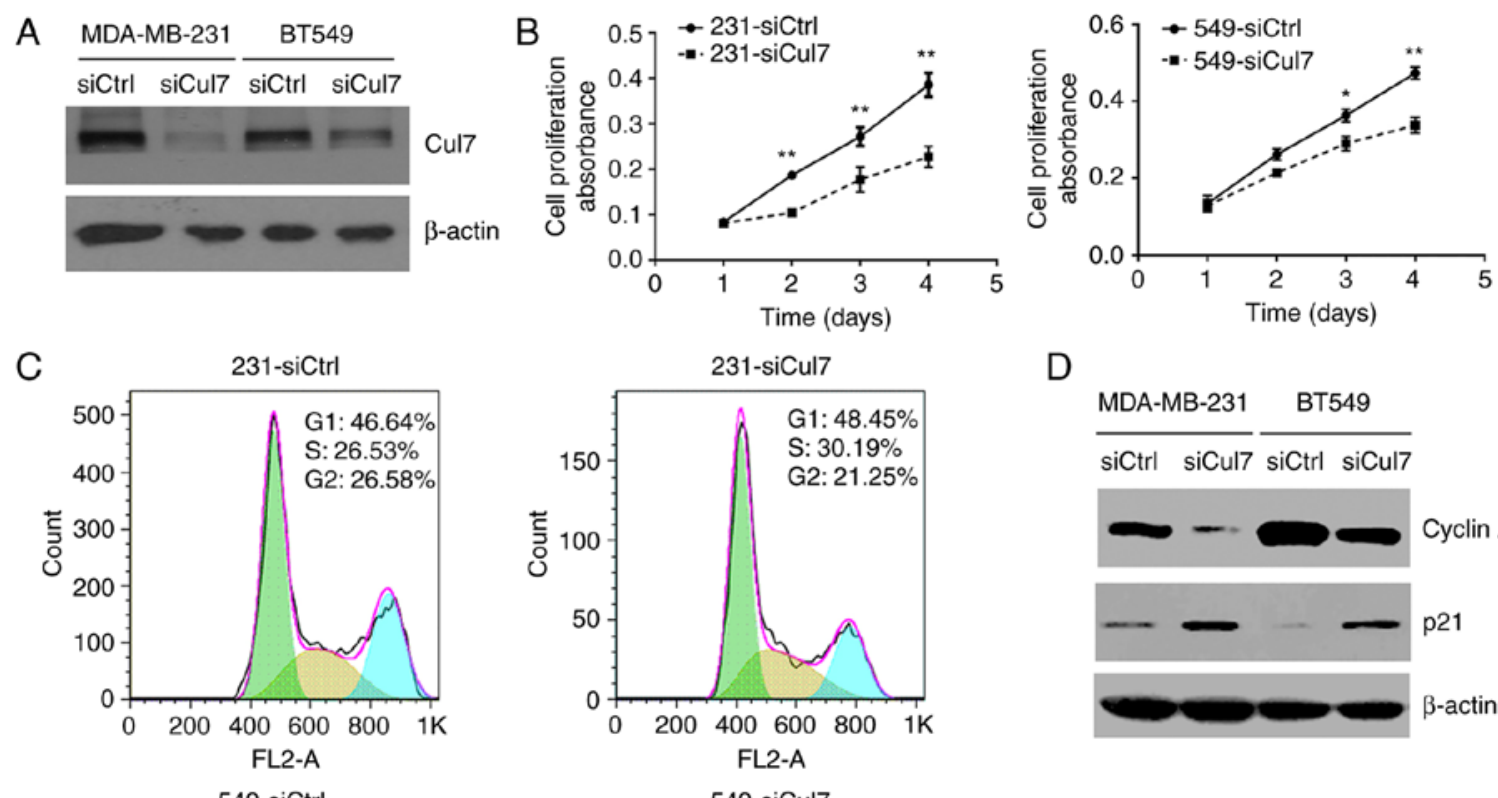

$\mathrm{D}$
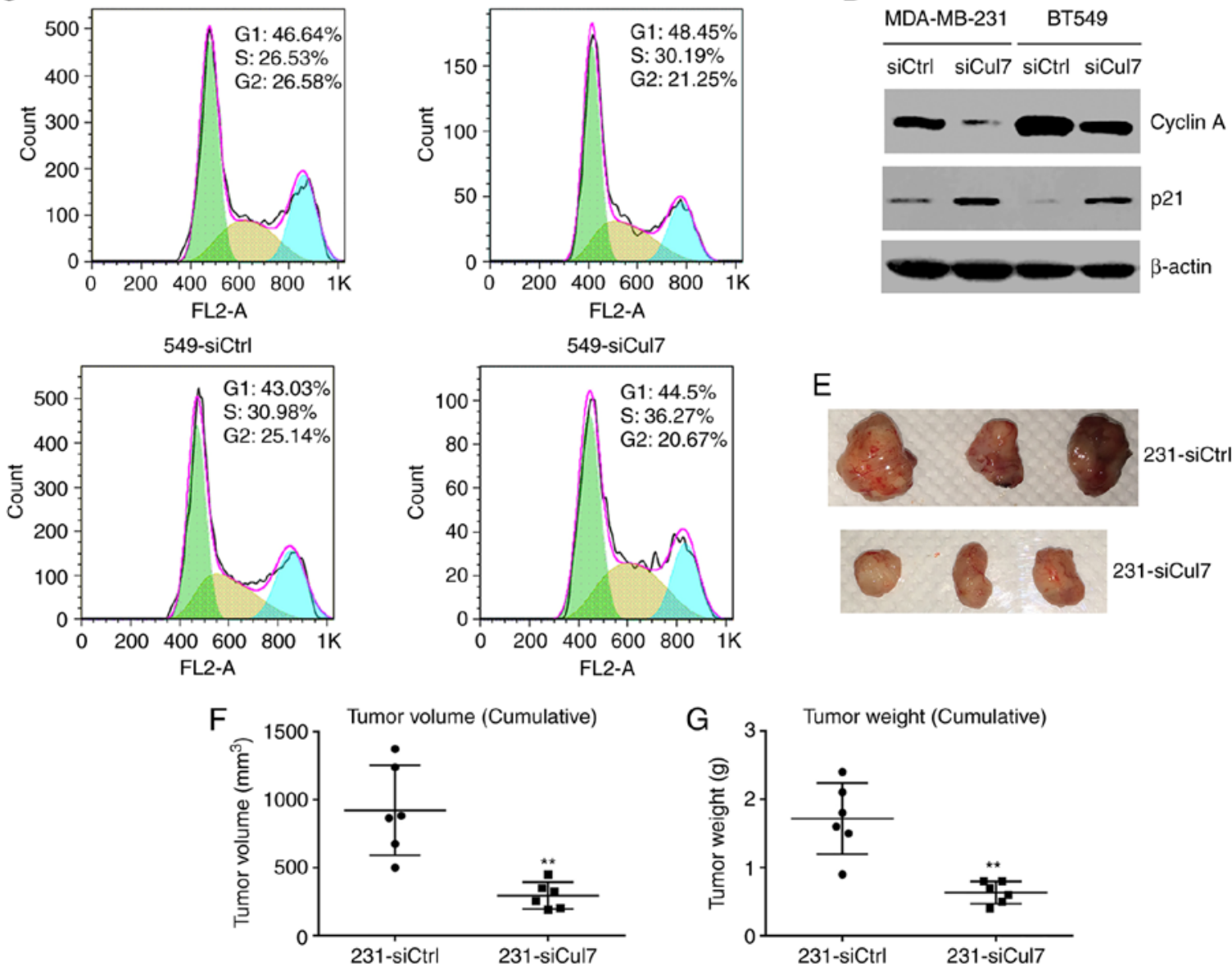

Figure 2. Knockdown of cullin 7 gene expression in breast cancer cells inhibits cell proliferation. (A) Western blotting of cullin 7 and $\beta$-actin protein expression in MDA-MB-231 and BT549 stable cells. 231-siCul7 and 549-siCul7, MDA-MB-231 and BT549 stable cells expressing cullin 7 siRNA. 231-siCtrl and 549-siCtrl, MDA-MB-231 and BT549 control stable cells expressing control siRNA. $n=3$ (each experiment was repeated 3 times). (B) Cell proliferation assay in MDA-MB-231 and BT549 stable cells. (C) Flow cytometry of the cell cycle in MDA-MB-231 and BT549 stable cells. n=3. (D) Western blotting of cyclin A and p21 protein expression in MDA-MB-231 and BT549 stable cells. $n=3$. (E) Representative images of tumors collected 48 days after cell inoculation. Nude mice were inoculated with 231-siCul7 and 231-siCtrl stable cells. (F) Cumulative tumor volume. (G) Tumor weight. Data are expressed as means $\pm \mathrm{SE}$ (n=5 or 6/group); ${ }^{*} \mathrm{P}<0.05 ;{ }^{* * *} \mathrm{P}<0.01$.

cells compared to that noted in the control cells (Fig. 2B). Cell cytometric assay showed that the percentage of cells in the S1 phase was significantly increased, but the percentage of cells in the G2 phase was significantly decreased in the 231-siCul7 and 549-siCul stable cells compared to these populations in the control cells $(\mathrm{P}<0.05)$ (Fig. 2C). Western blotting showed that the expression of cyclin A protein was significantly decreased, while p21 protein expression was significantly increased in the 231-siCul7 and 549-siCul7 stable cells compared to levels noted in the control cells $(\mathrm{P}<0.05)$ (Fig. 2D). These results suggest that the proliferation of breast cancer cells is associated with decreased cell cycle arrest.

The study of xenograft 231-siCul7 and 231-siCtrl cells in nude mice showed that silencing of cullin 7 expression
(231-siCul7) significantly decreased the tumor volume and weight compared to these parameters in the control group (231-siCtrl) (Fig. 2E-G).

Silencing of cullin 7 expression changes cell morphology. 231-siCul7, 549-siCul7, 231-siCtrl and 549-siCtrl cells were plated in $10-\mathrm{cm}$ plates and allowed to form small colonies for 6 days and were then observed to ascertain whether colonies maintained compact, loose or scattered contact with neighboring cells. After inhibiting cullin 7 expression, the growth of 231-siCul7 and 549-siCul7 cells changed from scatter growth to compact growth. The proportion of cells with compact growth was significantly increased in the 231-siCul7 $(60 \pm 2.5 \%)$ and 549 -siCul7 $(61.67 \pm 3.4 \%)$ cells compared to the 231 -siCtrl and 
A
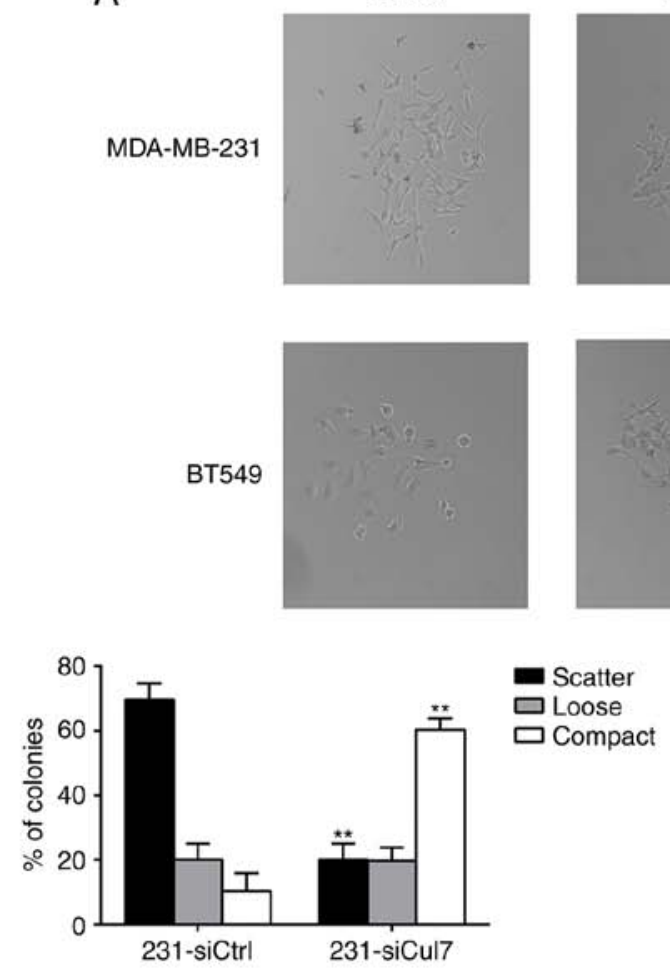

B
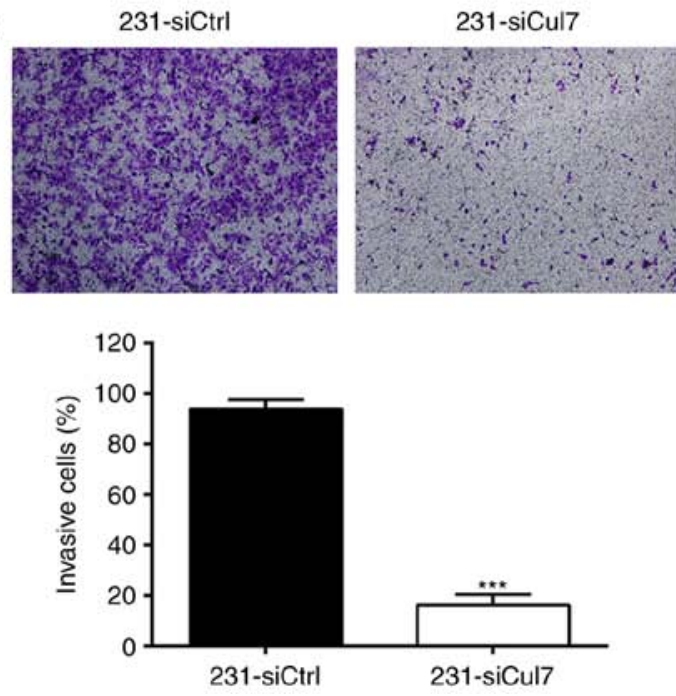
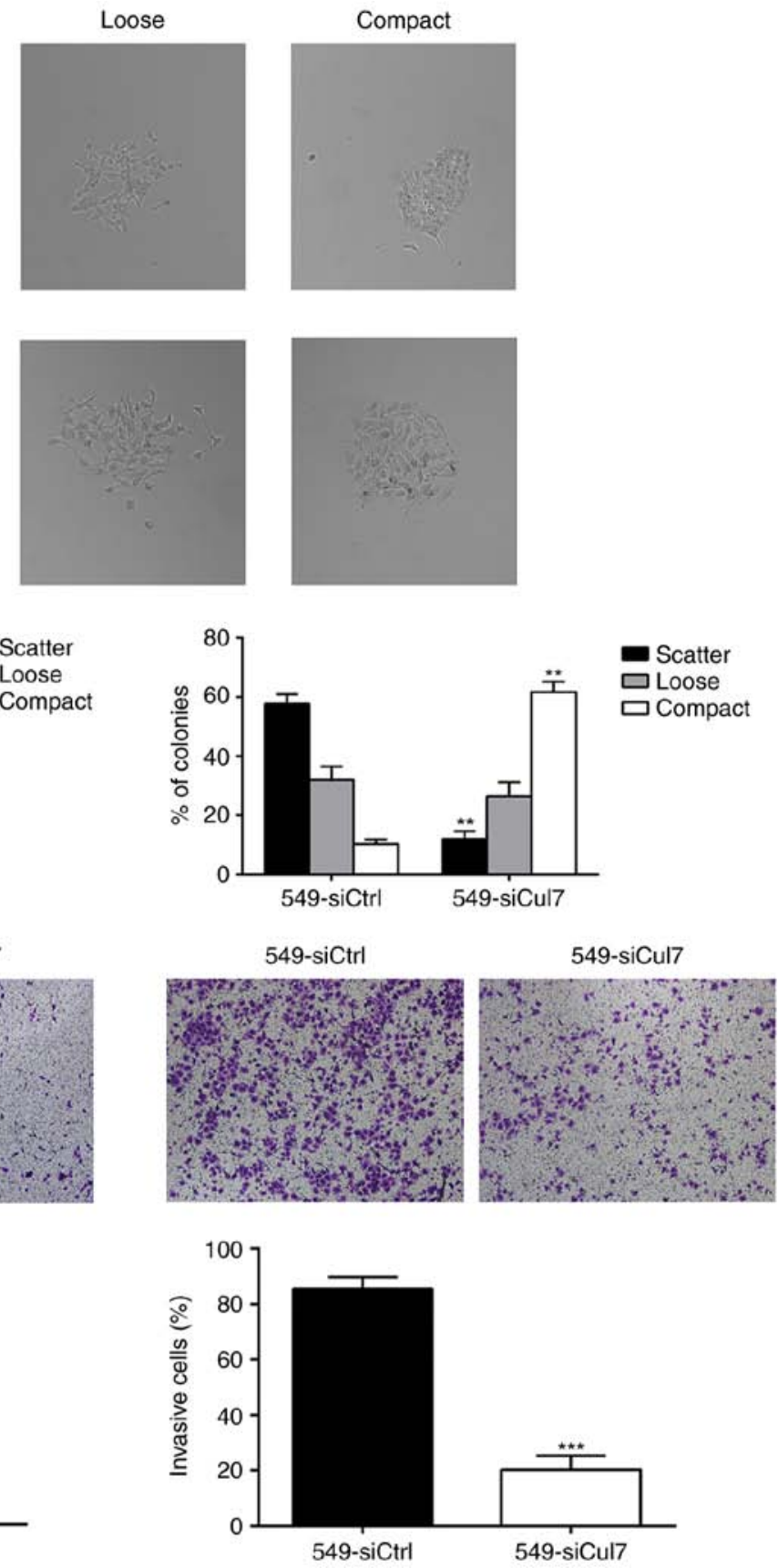

Figure 3. Knockdown of cullin 7 in breast cancer cells suppresses cell invasion. (A) Representative light microscopic images of MDA-MB-231 and BT549 cells at scatter, loose and compact growth (upper panel) and percentage of colonies (lower panel). Cells were plated in 10-cm plates and allowed to form small colonies for 6 days. 231-siCul7 and 549-siCul7, MDA-MB-231 and BT549 stable cells expressing cullin 7 siRNA. 231-siCtrl and 549-siCtrl, MDA-MB-231 and BT549 control stable cells expressing control siRNA. n=3. (B) Invasion assay of MDA-MB-231 and BT549 stable cells in Transwells covered with Matrigel. Upper panel, representative images of invasion assay. Lower panel, percentage of invaded cells. Data are expressed as means $\pm \mathrm{SE} ;{ }^{* *} \mathrm{P}<0.01,{ }^{* * *} \mathrm{P}<0.001 . \mathrm{n}=5$.

549-siCtrl cells $(10 \pm 2.7$ and $10.33 \pm 2.8 \%$, respectively, $\mathrm{P}<0.05)$ On the contrary, the proportion of cells with scatter growth was significantly decreased in the $231-\operatorname{siCul} 7(20 \pm 3.1 \%)$ and 549 -siCul7 $(12 \pm 2.5 \%)$ cells compared to the $231-$ siCtrl and 549-siCtrl cells $(69 \pm 3.8$ and $57.6 \pm 2.9 \%$, respectively, $\mathrm{P}<0.05$ ) (Fig. 3A).

Silencing of cullin 7 expression inhibits cell invasion. In vitro invasion assay showed that the number of 231-siCul7 and 549-siCul7 cells that passed the Matrigel was significantly less than the number of 231-siCtrl and 549-siCtrl cells $(\mathrm{P}<0.01)$ (Fig. 3B). These results suggest that cullin 7 is involved in the invasion of breast cancer cells.

Silencing of cullin 7 expression affects microtubule regeneration. The immunofluorescence of $\alpha$-tubulin showed that the morphology of 231-siCul7 and 549-siCul7 cells was transformed from normal fuselage into polygons, the cytoskeleton clarity decreased, the microtubule tissue around the nucleus was partially disappeared, and the microtubule was obviously disturbed (Fig. 4A). This suggests that silencing of cullin 7 expression affected the formation of pseudopodia 
A

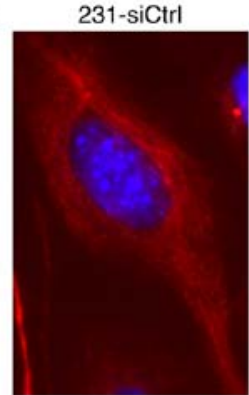

$\alpha$-tubulin, DAPI

B

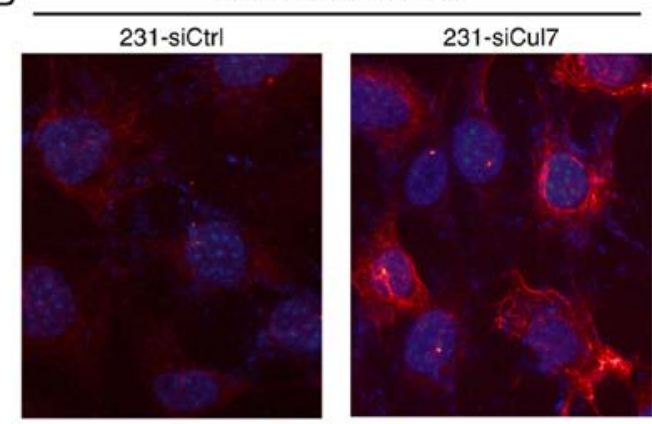

$\alpha$-tubulin, DAPI

231-siCul7

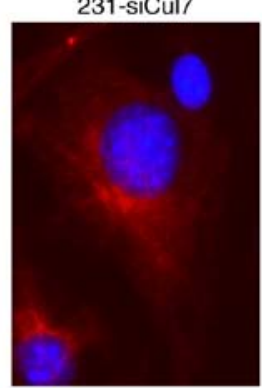

549-siCtrl

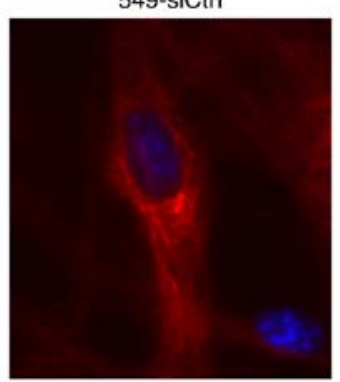

$\alpha$-tubulin, DAPI

nocodazole \& washout

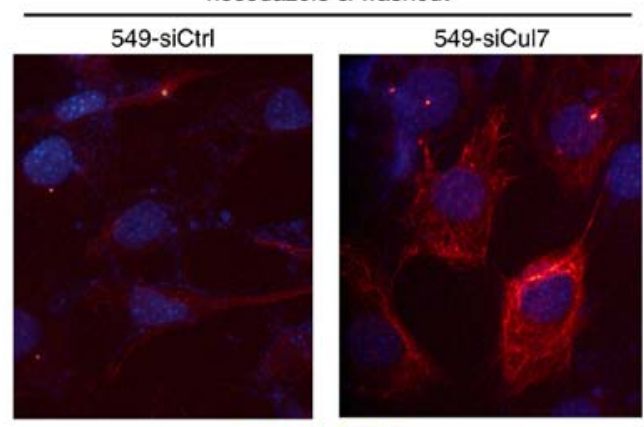

$\alpha$-tubulin, DAPI
549-siCul7

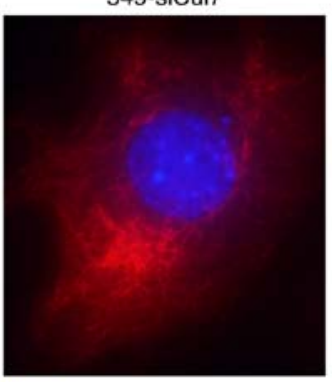

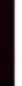


of cells (25-27). A previous study found that imbalance of polymerization and depolymerization dynamics inhibits the ability of tumor cells to form invasive pseudopodia, leading to a decrease in invasion and metastasis (28). It has been reported that abnormal function of tubulin cofactors can induce cell cycle arrest and apoptosis $(29,30)$. For example, the study on $3 \mathrm{M}$ syndrome found that cullin 7 mutation increased the stability of cell microtubules, prolonged or even stagnationed cell mitosis, and induced cell growth stagnation or aging (31). The present study revealed that silencing of cullin 7 expression in breast cancer cells decreased the cell proliferation and induced cell cycle arrest, such as increasing the proportion of cells in the $\mathrm{S}$ phase while reducing the proportion of cells in the $\mathrm{G} 2$ phase. The present study also showed that silencing of cullin 7 expression in MDA-MB-231 and BT549 cells changed the mode of cell growth and morphology with obvious disorder of microtubule dynamics, suggesting that cullin 7 promotes tumor cell invasion by affecting the cytoskeleton.

In conclusion, the present study suggests that positive cullin 7 expression is associated with the malignant phenotype of breast cancer and is a predictor of poor prognosis in breast cancer patients. Cullin 7 is involved in cell proliferation and invasion by regulating the cell cycle and microtubule stability. Therefore, cullin 7 can be used as a new biological marker for the early diagnosis and treatment of breast cancer.

\section{Acknowledgements}

The present study was supported by a grant from the Science Foundation of Guangdong Province (2013B021800301). We thank Professor Zhiming He for providing the reagents and breast cancer cell lines. We are also grateful to Dr Zhijie Zhang for providing the cell flow cytometry and cell cycle analysis.

\section{References}

1. Ding F, Xiao H, Wang M, Xie X and Hu F: The role of the ubiq uitin-proteasome pathway in cancer development and treatment Front Biosci 19: 886-895, 2014.

2. Jain CK, Arora S, Khanna A, Gupta M, Wadhwa G and Sharma SK: The ubiquitin-proteasome pathway an emerging anticancer strategy for therapeutics: A patent analysis. Recent Patents Anticancer Drug Discov 10: 201-213, 2015.

3. Kitagawa K and Kitagawa M: The SCF-type E3 ubiquitin ligases as cancer targets. Curr Cancer Drug Targets 16: 119-129, 2016.

4. Sarikas A, Hartmann T and Pan ZQ: The cullin protein family. Genome Biol 12: 220, 2011.

5. Zhao Y and Sun Y: Cullin-RING ligases as attractive anti-cancer targets. Curr Pharm Des 19: 3215-3225, 2013.

6. Min KW, Kim DH, Do SI, Sohn JH, Chae SW, Pyo JS, Park CH, Oh YH, Jang KS, Kim HL, et al: Diagnostic and prognostic relevance of Cullin1 expression in invasive ductal carcinoma of the breast. J Clin Pathol 65: 896-901, 2012.

7. Kim B, Nam HJ, Pyo KE, Jang MJ, Kim IS, Kim D, Boo K, Lee SH, Yoon JB, Baek SH, et al: Breast cancer metastasis suppressor 1 (BRMS1) is destabilized by the Cul3-SPOP E3 ubiquitin ligase complex. Biochem Biophys Res Commun 415: 720-726, 2011.

8. Saucedo-Cuevas LP, Ruppen I, Ximénez-Embún P, Domingo S, Gayarre J, Muñoz J, Silva JM, García MJ and Benítez J: CUL4A contributes to the biology of basal-like breast tumors through modulation of cell growth and antitumor immune response. Oncotarget 5: 2330-2343, 2014.

9. Wang H, Chen Y, Lin P, Li L, Zhou G, Liu G, Logsdon C, Jin J, Abbruzzese JL, Tan TH, et al: The CUL7/F-box and WD repeat domain containing 8 (CUL7/Fbxw8) ubiquitin ligase promotes degradation of hematopoietic progenitor kinase 1. J Biol Chem 289: 4009-4017, 2014.
10. Xu X, Sarikas A, Dias-Santagata DC, Dolios G, Lafontant PJ, Tsai SC, Zhu W, Nakajima H, Nakajima HO, Field LJ, et al: The CUL7 E3 ubiquitin ligase targets insulin receptor substrate 1 for ubiquitin-dependent degradation. Mol Cell 30: 403-414, 2008.

11. Guo H, Wu F, Wang Y, Yan C and Su W: Overexpressed ubiquitin ligase Cullin7 in breast cancer promotes cell proliferation and invasion via down-regulating p53. Biochem Biophys Res Commun 450: 1370-1376, 2014.

12. Fu J, Lv X, Lin H, Wu L, Wang R, Zhou Z, Zhang B, Wang YL, Tsang BK, Zhu C, et al: Ubiquitin ligase cullin 7 induces epithelial-mesenchymal transition in human choriocarcinoma cells. J Biol Chem 285: 10870-10879, 2010.

13. Li H, Yang B, Xing K, Yuan N, Wang B, Chen Z, He W and Zhou J: A preliminary study of the relationship between breast cancer metastasis and loss of heterozygosity by using exome sequencing. Sci Rep 4: 5460, 2014.

14. Wu J, He Z, Wang DL and Sun FL: Depletion of JMJD5 sensitizes tumor cells to microtubule-destabilizing agents by altering microtubule stability. Cell Cycle 15: 2980-2991, 2016.

15. Zhang D, Yang G, Li X, Xu C and Ge H: Inhibition of liver carcinoma cell invasion and metastasis by knockdown of Cullin7 in vitro and in vivo. Oncol Res 23: 171-181, 2016.

16. Men X, Wang L, Yu W and Ju Y: Cullin7 is required for lung cancer cell proliferation and is overexpressed in lung cancer. Oncol Res 22: 123-128, 2015.

17. Kim SS, Shago M, Kaustov L, Boutros PC, Clendening JW, Sheng Y, Trentin GA, Barsyte-Lovejoy D, Mao DY, Kay R, et al: $C U L 7$ is a novel antiapoptotic oncogene. Cancer Res 67: 9616-9622, 2007.

18. Xi J, Zeng ST, Guo L and Feng J: High expression of Cullin7 correlates with unfavorable prognosis in epithelial ovarian cancer patients. Cancer Invest 34: 130-136, 2016.

19. Bendris N, Lemmers B, Blanchard JM and Arsic N: Cyclin A2 mutagenesis analysis: A new insight into CDK activation and cellular localization requirements. PLoS One 6: e22879, 2011.

20. Pagano M, Pepperkok R, Verde F, Ansorge W and Draetta G: Cyclin A is required at two points in the human cell cycle. EMBO J 11: 961-971, 1992.

21. Yam CH, Fung TK and Poon RY: Cyclin A in cell cycle control and cancer. Cell Mol Life Sci 59: 1317-1326, 2002.

22. De Boer L, Oakes V, Beamish H, Giles N, Stevens F, Somodevilla-Torres M, Desouza C and Gabrielli B: Cyclin $\mathrm{A} / \mathrm{cdk} 2$ coordinates centrosomal and nuclear mitotic events. Oncogene 27: 4261-4268, 2008.

23. Henglein B, Chenivesse X, Wang J, Eick D and Bréchot C: Structure and cell cycle-regulated transcription of the human cyclin A gene. Proc Natl Acad Sci USA 91: 5490-5494, 1994.

24. Gartel AL and Radhakrishnan SK: Lost in transcription: p21 repression, mechanisms, and consequences. Cancer Res 65: 3980-3985, 2005.

25. Amos LA: What tubulin drugs tell us about microtubule structure and dynamics. Semin Cell Dev Biol 22: 916-926, 2011.

26. Nogales E: An electron microscopy journey in the study of microtubule structure and dynamics. Protein Sci 24: 1912-1919, 2015.

27. Szarama KB, Gavara N, Petralia RS, Kelley MW and Chadwick RS: Cytoskeletal changes in actin and microtubules underlie the developing surface mechanical properties of sensory and supporting cells in the mouse cochlea. Development 139: 2187-2197, 2012.

28. Carranza G, Castaño R, Fanarraga ML, Villegas JC, Gonçalves J, Soares H, Avila J, Marenchino M, Campos-Olivas R, Montoya G, et al: Autoinhibition of TBCB regulates EB1-mediated microtubule dynamics. Cell Mol Life Sci 70: 357-371, 2013.

29. Bendre S, Rondelet A, Hall C, Schmidt N, Lin YC, Brouhard GJ and Bird AW: GTSE1 tunes microtubule stability for chromosome alignment and segregation by inhibiting the microtubule depolymerase MCAK. J Cell Biol 215: 631-647, 2016.

30. Gergely ZR, Crapo A, Hough LE, McIntosh JR and Betterton MD: Kinesin- 8 effects on mitotic microtubule dynamics contribute to spindle function in fission yeast. Mol Biol Cell 27: 3490-3514, 2016.

31. Yan J, Yan F, Li Z, Sinnott B, Cappell KM, Yu Y,Mo J, Duncan JA, Chen X, Cormier-Daire V, et al: The $3 \mathrm{M}$ complex maintains microtubule and genome integrity. Mol Cell 54: 791-804, 2014. 